\title{
Bioética e morte assistida: liberdade para morrer?
}

\author{
Bioethics and assisted death: freedom to die? \\ Bioética y muerte asistida: ¿libertad para morir?
}

Recebido: 25/04/2021 | Revisado: 30/04/2021 | Aceito: 04/05/2021 | Publicado: 18/05/2021

\author{
Amanda Maria Silva da Cunha \\ ORCID: https://orcid.org/0000-0001-7652-9558 \\ Universidade Federal de Alagoas, Brasil \\ E-mail: amandamsc29@gmail.com \\ Hallana Laisa de Lima Dantas \\ ORCID: https://orcid.org/0000-0001-6721-0860 \\ Universidade Federal de Alagoas, Brasil \\ E-mail: lanavidas@hotmail.com \\ Sílvia Alves dos Santos \\ ORCID: https://orcid.org/0000-0002-3131-3726 \\ Universidade Federal de Alagoas, Brasil \\ E-mail:silviaphaiffer@hotmail.com \\ Isabel Comassetto \\ ORCID: https://orcid.org/0000-0002-2389-9384 \\ Universidade Federal de Alagoas, Brasil \\ E-mail: isabel.comassetto@eenf.ufal.br \\ Regina Maria dos Santos \\ ORCID: https://orcid.org/0000-0002-2144-2997 \\ Universidade Federal de Alagoas, Brasil \\ E-mail: relpesantos@gmail.com
}

\begin{abstract}
Resumo
O objetivo deste trabalho é reunir elementos que permitam refletir sobre o dilema ético acerca da morte assistida, considerando o princípio da preservação da vida e a liberdade para morrer promovida pela autonomia do homem na decisão sobre finitude. Trata-se de um estudo de reflexão realizado em três passos: a busca de literatura que abordasse a temática, o resgate de casos da experiência dos autores que inspirassem situações fictícias demonstrativas do dilema, a escrita de textos que apresentassem a questão e promovessem o diálogo. Demonstra-se que a questão tornou-se extremamente complexa, envolvendo temas como as tecnologias da morte, o discurso transhumanista e o cuidado de doentes terminais, levantando questões bioéticas, filosóficas e políticas, indicando que a liberdade para morrer relaciona-se com a aceitação da morte como uma etapa natural e inequívoca do ciclo da vida e o poder que o ser tem sobre si em seu próprio processo de morte.
\end{abstract}

Palavras-chave: Morte; Direito a morrer; Bioética; Autonomia pessoal; Liberdade.

\begin{abstract}
The objective of this work is to gather elements that allow reflecting on the ethical dilemma about assisted death, considering the principle of preserving life and the freedom to die promoted by human's autonomy in the decision on finitude. It is a reflection study carried out in three steps: the search for literature that addressed the theme, the rescue of cases from the authors' experience that inspired fictional situations demonstrating the dilemma, the writing of texts that presented the issue and promoted dialogue. It is shown that the issue has become extremely complex, involving themes such as death technologies, transhumanist discourse and the care of terminally ill patients, raising bioethical, philosophical and political issues, indicating that freedom to die is related to acceptance of death as a natural and unambiguous stage of the life cycle and the power that the human has over itself in its own process of death.
\end{abstract}

Keywords: Death; Right to die; Bioethic; Personal autonomy; Freedom.

\section{Resumen}

El objetivo de este trabajo es reunir elementos que permitan reflexionar sobre el dilema ético de la muerte asistida, considerando el principio de preservación de la vida y la libertad de morir que promueve la autonomía del hombre en la decisión sobre la finitud. Se trata de un estudio de reflexión realizado en tres pasos: la búsqueda de literatura que abordó el tema, el rescate de casos de la experiencia de los autores que inspiraron situaciones de ficción demostrando el dilema, la redacción de textos que presentaban el tema y promovieron el diálogo. Se muestra que el tema se ha vuelto extremadamente complejo, involucrando temas como tecnologías de la muerte, discurso transhumanista y atención a pacientes terminales, planteando cuestiones bioéticas, filosóficas y políticas, indicando que la libertad de 
morir está relacionada con la aceptación de la muerte como una natural y inequívoca etapa del ciclo vital y el poder que el hombre tiene sobre sí mismo en su propio proceso de muerte.

Palabras clave: Muerte; Derecho a morir; Bioética; Autonomía personal; Libertad.

\section{Introdução}

As discussões a respeito da morte e do processo de morrer ganharam novos significados e interesses, atualmente, com a tecnologia disponível para o cuidado dos enfermos, a vertente que se coloca é sobre padronizar e criar direitos para empoderar o indivíduo sobre seu próprio processo de finitude ou para garantir a inviolabilidade e respeito do corpo cadavérico. Esta questão é negligenciada ou desvelada de acordo com o estado de desenvolvimento e cultura da sociedade ao longo da história. A exemplo, o misticismo e a filosofia imprimem significados para este fenômeno que refletem o perfil do contexto social em que se fala sobre morte (Ariès, 2012).

Reconhecer o fim da existência como visto atualmente cria paradoxos com o modelo de saúde vigente no ocidente, a medicina curativa. O aprimoramento tecnológico alcançou a área da saúde com força e grande repercussão (Ariès, 2012). Adoecimentos que há muito eram anunciados com baixa expectativa de sobrevida, hoje encontram múltiplas abordagens terapêuticas. A expectativa de vida do homem foi prolongada com os avanços na área da saúde, na direção do interesse humano que não se perdeu com o tempo qual seja o distanciar-se da morte (Kovács, 2014).

O desejo pela longevidade sempre esteve fortemente associado a crenças religiosas e místicas sobre o valor da alma humana em uma imortalidade além-túmulo, uma existência além do corpo. No entanto, hodiernamente estruturado por uma nova conjuntura de poder concreto sobre o corpo, o desejo pela longevidade sustenta-se em práticas e tecnologias em saúde inovadoras, capazes de substituir e prover funções vitais como respiração no corpo e pelo corpo através de ventiladores mecânicos invasivos, tudo em prol da manutenção da vida, mas será que realmente vale tudo para manter o corpo vivo? Em que tipo de vida?

Questionamentos como estes surgem paralelamente à forte medicalização e normalização da vivência do processo de morrer. A hospitalização e a assistência intervencionista ocuparam as lacunas entre o dilema de salvar vidas e a dignidade no processo de morte do indivíduo. Os princípios bioéticos da autonomia e da não-maleficência se digladiam diante deste padrão de serviço hospitalar carregado de intervenções que interrompem o que há muito se anuiu a chamar de processo natural do ciclo da vida. Hoje, o que se vê são pessoas em processo de finitude, cujo sofrimento físico e/ou psíquico frequentemente têm suas referências de dignidade, conforto e não-maleficência resignificadas (Santos, 2019).

Não obstante, a gestão da vida predetermina as condições aceitáveis da existência, bem como o curso de sua finitude, indiferente a vontade do ser que existe, ação na qual o Estado desempenha o biopoder sobre os corpos de forma individual ou coletivamente mediante metaparadigmas e intervenções políticas, regulando os modos de viver, a biopolítica (Furtado \& Oliveira Camilo, 2016).

Baseado em valores morais, a Bioética propõe a autonomia como princípio, que nesta situação defronta-se com um outro, o princípio da não maleficência, em casos em que os indivíduos não têm mais perspectivas de cura, encontram-se em sofrimento físico e psíquico e anseiam por alguma maneira de interromper a vida ou ainda querem suspender os aparelhos e medicações que mantém artificialmente as funções fisiológicas, situações que são conhecidas como morte assistida, distanásia, eutanásia e ortotanásia (Ramos \& Franco, 2020).

As escolhas existenciais de um indivíduo que experiencia o processo do morrer tendem a se alinhar com as suas perspectivas e prospecções, afetos, vontades, prognóstico clínico e um bem-estar subjetivo que são significados e ressignificados durante o dinâmico estado saúde-doença. Inserir estes elementos à compreensão da natureza complexa da vida e morte, permite uma aproximação das respostas aos dilemas da bioética em torno da individualidade e voluntariedade do ser sobre seu próprio fim (Santos, 2019). 
Diante do exposto, tem-se como objetivo para esse trabalho reunir elementos que permitam refletir sobre o dilema ético que cerca a morte assistida, considerando de um lado o princípio da preservação da vida e do outro a liberdade para morrer promovida pela autonomia do sujeito em decidir sobre a sua finitude.

\section{Metodologia}

Para promover a reflexão proposta, três passos foram seguidos, à guisa de organização dos argumentos: primeiramente procedeu-se uma busca de literatura recente que abordasse a questão da finitude da vida e dos princípios bioéticos da autonomia e não maleficência, ambos imbricados em qualquer discussão a respeito da morte assistida. Os artigos, dissertações e teses publicados encontrados foram triados pela pertinência do conteúdo e foram inseridos no texto desde a contextualização do tema até a discussão dos argumentos encontrados.

O segundo passo foi resgatar da experiência dos autores casos que inspirassem situações fictícias demonstrativas do dilema vivido pelos sujeitos e que criam impactos para a equipe de saúde, responsável pelo cuidado e pela preservação da vida. Foram construídos três casos e um foi relatado em literatura publicada, havendo o cuidado de indicar a respectiva fonte; com base nos passos anteriores, a terceira etapa, que remete a apresentação dos resultados e discussão reflexiva foi a escrita de textos que a) apresentaram a questão, b) rememoraram o significado de morte na sociedade, conceituaram o que se traduziu nesse estudo por "liberdade para morrer" e c) promoveram o diálogo dos autores sobre a morte assistida sob a forma de distanásia, eutanásia e ortotanásia. É o que se apresenta a seguir.

\section{Resultados e Discussão}

O que se pensa sobre o processo de morte e vida foi construído sobre fundamentos históricos, sociais, espirituais, filosóficos e culturais de maneira gradual, que serão discutidos a seguir com base no confronto de modos de pensar o morrer e cada processo de morte, bem como a autonomia e liberdade individual para viver ou morrer.

\subsection{Para apreender a questão}

Para melhor contextualizar o tema, alguns casos fictícios de pessoas em estado crítico de saúde trazem os elementos essenciais para análise da questão. O primeiro deles é M.J.S., sexo feminino, 70 anos, com câncer de pele do tipo melanoma apresentando rosto esteticamente deformado, com várias metástases, em situação de grande sofrimento físico e mental, tinha vergonha de ir ao hospital para as pessoas não verem sua anomalia/monstruosidade. O segundo trata-se de J.M.D., sexo masculino, 15 anos, em coma irreversível devido acidente de moto, portador de traqueostomia, jejunostomia, vários cateteres e infecções recorrentes e uma família que não tinha condições de mantê-lo fora do hospital. O terceiro, C.S.C., sexo masculino, 30 anos, diagnosticado com câncer de pênis em estado bastante avançado, consternado pelas fortes dores e sofrimento, grita pedindo a Deus para tirá-lo dessa angústia.

Ainda, quando se pensa no caso de um adulto jovem que vive intensamente até desenvolver Esclerose Lateral Amiotrófica (ELA) onde se perde aos poucos a capacidade motora e o poder de usufruir de uma vida plena, vivendo em estado de alta dependência, clarifica a dicotomia entre aplicar as tecnologias intervencionistas em saúde para permanecer vivo, independente da condição e dispor destas a fim de amenizar os sofrimentos (Azeredo Orselli, \& Faissel, 2020).

Nos casos citados e em tantos outros que podem ser acompanhados nas instituições de saúde e espaços domiciliares assistidos, os sujeitos e seus familiares reconhecem o prolongamento da vida como algo penoso e doloroso. O padecimento relacionado às suas condições de saúde levou os envolvidos a reconhecerem na morte a libertação de sua consternação. Nesses casos, a continuidade da vida não remete a um milagre, mas a um sofrimento, onde a liberdade de morrer se apresenta 
pacificamente diante da autonomia do sujeito, contrapondo-se à corrida pela longevidade.

Criar limites para as abordagens em saúde, não aceitar a morte, impedir ou tolher a autonomia do sujeito sobre seu processo de finitude e saúde-doença alcançam meandros que enveredam pelas normatizações bioéticas, dividem opiniões e legalidades dentro dos países ocidentais. A tomada de decisão sobre o fim da vida parte de um paradoxo que põe em evidência duas faces, de um lado se tem os intermináveis esforços na evitação da morte, prolongamento da vida através de tecnologias e de outro a premissa do direito sobre si, o direito de morrer, acessar a terminalidade da vida com conforto, tal qual propõe os cuidados paliativos em fim de vida (Benedides, 2018; Pazinatto, 2019).

Diante disto, uma reflexão teórica baseada na análise de informações disponíveis a respeito da liberdade e autonomia do indivíduo acerca do seu próprio processo de finitude seja por distanásia, eutanásia, ortotanásia ou suicídio assistido, deve ser ponderada pelos princípios bioéticos e atenção ao conceito de poder formulado por Michel Foucault, o qual considera que poder é a capacidade que o Estado tem de dar ordens aos cidadãos. Dessa forma o poder evoca a ideia de força, capacidade de governar e de obter obediência destes. Enquanto a autonomia reflete o poder individual, os esforços tecnológicos para salvar vidas representam o poder coletivo do Estado em suas políticas públicas.

\subsection{Para compreender o significado da morte}

A morte é o último estágio do ciclo da vida, é inevitável, mas ultimamente tem sido um evento adiável. Embora todos os indivíduos tenham ciência de sua mortalidade, a cultura ocidental criou tabus em torno do seu processo, através de incansáveis desvios e dissensões quanto ao manejo (Kovács, 2014).

O morrer nem sempre foi tão carregado de estigmas. Na idade média, o seu significado estava naturalmente associado à finitude, identificando o fim da vida, dispensando cerimônias e procissões, ocorria em ambiente familiar como um evento biológico, histórico e social. O advento da urbanização e aglomeração popular, aprimoramento das ciências do espírito, o desenvolvimento técnico-científico e implantações destas descobertas no setor da saúde em suporte à vida acabou por adiar a morte, ou mesmo prolongá-la. E assim, as mortes deixaram de ocorrer no seio da família para ocorrer no hospital, cercado por aparelhos e profissionais altamente instrumentalizados (Kovács, 2014; Benedides, 2018).

Desde então, a morte foi incorporada ao cotidiano agitado nos hospitais, sobretudo nas Unidades de Terapia Intensivas (UTI's), uma vez que se trata de um local com um perfil de paciente muito específico, que demanda atendimento ininterrupto com procedimentos, invasivos, complexos e especializados. Assim, estruturalmente as UTI's são setores restritos que contam com largo investimento tecnológico, profissionais de saúde com proporcional capacitação em conhecimentos e habilidades para a realização dos procedimentos.

A estranheza à morte humana não é tema recente de estudos e análises, tampouco uma discussão ausente do ambiente hospitalar, mas uma inquietação antiga que se conserva heterogênea e sem consenso ao longo da formação histórica do pensamento ocidental, nos mitos gregos, multiplicidade religiosa e ciências do espírito (Ramos \& Franco, 2020). Também esteve presente na doutrina da imortalidade da alma de Platão através do diálogo Fédon, nas considerações sobre ética de Epicuro, nas Confissões de Santo Agostinho, nos Ensaios de Montaigne, na Ética de Espinosa, nas antinomias da razão de Kant, na metafísica de Schopenhauer, e de maneira extensiva na Fenomenologia e no Existencialismo e nos seus posteriores influenciados, como Camus, Jaspers, Sartre, Heidegger, Gadamer (Tasca, 2020; Jesus Barbosa, \& Ribeiro, 2018).

Contudo, é a partir do século XX que os avanços tecnológicos, precursores de mudanças psicossociais, tornam-se indissociáveis do modo de agir e pensar em sociedade, isto é, as normas, o saber, a disciplina e as regulamentações moral e ética operaram ponderando as atualizações e necessidades existenciais do homem daquele contexto. A transformação que a revolução técnico-científica agrega às ciências biológicas fortalece as intervenções no ciclo da vida sistemática e filosoficamente, figurando um processo de vida-morte medicalizado fisiológico e orgânico (Ramos \& Franco, 2020). 
As relações de poder e saber em torno da morte se modificaram ao longo dos últimos três séculos. De acordo com Ariès (2012), o ser humano apresenta alguns comportamentos perante a morte, mostramos a seguir: a morte domada, consiste na imagem que caracterizava a morte na alta Idade Média, era esperada de forma natural, no meio da família e amigos, concebida no coletivo, a morte de si mesmo, entre os séculos XIV-XV, corresponde a uma individualização da morte e o reconhecimento do homem de si mesmo, ou seja, um autoreconhecimento; a morte do outro, datada nos séculos XVI-XVIII corresponde à visão da morte como cruel e dolorosa.

A morte interdita, a morte do século XX, apresenta mudanças extremas, ao moribundo é ocultada a real gravidade de seu estado e de sua enfermidade. O leito de morte, que normalmente era em casa rodeado pela família, é transferido para o hospital. Neste cenário, a morte tornou-se estranha e selvagem por já não ser mais familiar e próxima (Ariès, 2012; Santiago \& Deplagne, 2019).

A normalização por meio destas ciências se apresenta como um poder coercitivo sobre o corpo que difere da perspectiva existencial da comunidade fenomenóloga de Husserl e seus sucessores. É indiscutível os benefícios garantidos pelo desenvolvimento das ciências biológicas e da saúde para o tratamento de pacientes gravemente enfermos, mas a possibilidade de postergar a morte por tempo indefinido - ou a contravenção da vontade e credo do paciente - é uma face da mesma moeda. Esta circunstância ignora o significado da morte e confunde o valor da vida a qualquer custo (Ramos \& Franco, 2020; Praxedes, Araújo, \& Nascimento, 2018).

Neste ínterim, discutir o significado da morte e do morrer transcorre robustas discussões como as do pensador alemão Heidegger, que defende o valor de existir no tempo, sendo o tempo um determinante em significar e valorar a vida na morte e a condição de existir implica inequivocamente e findar. Assim utiliza-se em excesso recursos artificiais para prolongar a vida e manter ou prover as funções vitais sem o mínimo respeito à dignidade humana e individualidade do paciente.

O interesse em compreender o significado do morrer tem se tornado elemento central em investigações antropológicas devido a proeminência de dilemas éticos frente ao processo de morte e o poder das tecnologias interventivas do morrer (Ramos \& Franco, 2020). Dessarte, estudos qualitativos indicam que os profissionais de saúde compreendem a morte como um processo natural e inevitável (Benedides, 2018). Isso não os livra dos dilemas existentes no processo decisório (Praxedes et al., 2018).

\subsection{O que é liberdade para morrer?}

A liberdade para morrer corresponde à autonomia de vontade de um cidadão que está diretamente relacionada com o princípio do consentimento, no qual o indivíduo livre tem o direito de decidir seu próprio modo de viver e de morte. As pessoas competentes possuem o direito de buscar a realização de uma vida boa e plena no seu ponto de vista, bem como uma boa morte, pois possuem liberdade de morrer como decidirem, mesmo que essa escolha não seja tomada no momento adequado (Azeredo Orselli, \& Faissel, 2020).

Um indivíduo não tem poder sobre o início de sua vida, sua concepção e nascimento depende da vontade de terceiros. Porém, ao nascer adquire personalidade jurídica e aptidão para direitos e obrigações. Assim, o direito à vida é o primeiro direito de qualquer pessoa, sendo defendido pela constituição brasileira. Concomitante à aquiescência fundamental à vida defende-se igualmente a dignidade da pessoa humana, pois uma vida digna é a razão principal que mobiliza o processo civilizatório (Barroso \& Martel, 2010). O direito de escolha individual e, sobretudo, o livre arbítrio constituem-se como referenciais centrais no debate sobre a morte assistida na contemporaneidade.

Uma pessoa deve ter o poder sobre o fim da sua vida, uma vez que a morte é inevitável e inerente à condição humana, não devendo-se haver interferências na capacidade de cogitar antecipá-la. Entretanto, observa-se que a legitimidade ou não dessa escolha recebe influência religiosa, moral, filosófica e jurídica (Barroso \& Martel, 2010). Essa influência exercida 
corrobora com o pensamento de Michel Foucault para quem o poder emana de uma fonte que o detém e pode deixar fluir. Dessa forma o poder provém de uma autoridade, instituição que não apenas o possui, mas determina sua natureza, seus limites e seu modo de funcionamento.

Nesse sentido, Foucault entende o poder como um conjunto de relações assimétrica entre indivíduos, entre grupos, que se irradia da periferia para o centro, de baixo para cima, que se exerce permanentemente, sustentando as instâncias de autoridade e que funciona positivamente, dinamizando, incrementando as forças e recursos existentes (Barroso \& Martel, 2010). Para ele o poder não é uma coisa, mas um exercício desenvolvido através de uma rede que interconecta todo tecido/corpo social (Albuquerque, 1995).

Sabe-se que o poder de disciplina e adestramento sobre indivíduos, ocorre em instituições de confinamento, na expectativa de regulação da coletividade. Busca-se, portanto, gerir a vida, por meio de um poder cada vez maior para intervir no fazer viver e como viver, em detrimento do poder menor de fazer morrer, controlar seus acidentes, suas eventualidades, suas deficiências, daí por diante a morte (Santos, 2016). Logo, o Estado pode controlar quem deverá morrer e quem deverá viver, por meio de um sistema de seleção desigual.

Faz-se imprescindível considerar a morte como fenômeno imanente à condição humana. Sabe-se que nem mesmo com todo leque de possibilidades ofertadas pela tecnologia no tratamento e combate às doenças é possível impedir a morte em alguns casos incompatíveis com a vida, apenas prolongá-la sem perspectiva e qualidade. Nesta condição argumentos como "a vida é sagrada e pertence a Deus" já não são suficientes, uma vez que o sofrimento do indivíduo pode chegar ao ponto de fazêlo desejar a própria morte (Barroso \& Martel, 2010; Mesquita, 2019).

\subsection{Debatendo a possibilidade de haver liberdade para morrer}

Diante dos avanços inseridos na área da saúde nas últimas décadas, traduzidos em novos medicamentos e recursos tecnológicos que auxiliam no alcance da tão desejada cura, a morte passou a ser considerada como "resultado acidental" do processo de saúde doença (Ariès, 2012). Associado a isto, acompanhou-se a desnaturalização e temerosidade da morte que teve seu cenário transferido para os ambientes hospitalares caracterizados por drogas e equipamentos invasivos que, na busca pela recuperação da saúde acabam, em algumas situações, prolongando a morte (Schmitz et al., 2020).

Apesar da melhoria na qualidade de vida apresentada por tais avanços tecnológicos e biotecnológicos, não se pode negar a ocorrência de episódios de prolongamento desnecessário da vida e tratamentos injustificáveis como a obstinação terapêutica a qualquer custo (de Azeredo Orselli, \& Faissel, 2020; da Maia Pawlowytsch, \& Kovalski, 2017). Salienta-se que esse progresso tecnológico traz muitas incertezas e crises de humanismo, eis que junto com os benefícios vieram também preocupações de toda ordem, inclusive éticas e morais (Mendes et al., 2020). Nesse sentido, faz-se necessário e urgente analisar o preceito constitucional da dignidade da pessoa humana e sua autonomia, quando o paciente em estado de grande dor e sofrimento, opta por abrir mão de sua própria vida.

Deve-se considerar que o direito à vida assegurado perante a declaração dos direitos humanos não é mutuamente inclusivo do adiamento da morte por aqueles detentores dos instrumentos e conhecimentos necessários para essa prática, quando esta apresenta-se propínqua e natural (Marreiro, 2013). Considerando-se que essas práticas podem gerar dor e sofrimento ao doente, Tavares (2016) ressalta que o artigo cinco desta mesma declaração que assegura que "nenhum indivíduo deverá ser submetido a tratamentos degradantes e, por vezes, desumanos".

Os aspectos apresentados incitam discussões relacionadas aos termos suicídio assistido, distanásia, eutanásia e ortotanásia, sendo necessária à sua diferenciação. O suicídio assistido consiste no ato de auxiliar outras pessoas que não conseguem sozinhas finalizar sua própria vida oferecendo-lhe meios para tal (Brito, \& Leal, 2015). Esse auxílio pode consistir em prescrever doses letais de medicamentos, ajudar no processo de ingestão ou administração venosa e também pelo apoio e 
encorajamento do ato suicida (Kovács, 2015).

Este não deve ser confundido com a eutanásia (denominação advinda dos termos gregos dys e thánatos, que significam, respectivamente "ato defeituoso" e "morte"), que consiste na ação de uma pessoa abreviar a vida de outra com a intenção de evitar o sofrimento resultante de uma condição de vida dolorosa ou considerada indigna e degradante (Mendes et al., 2020; Kovács, 2015). Por sua vez, o vocábulo distanásia, advindo dos termos gregos dys e thánatos, que significam, respectivamente "ato defeituoso" e "morte", apresenta o conceito de uma morte difícil decorrente do prolongamento incongruente da vida, e o consequente adiamento doloroso da morte. $\mathrm{O}$ conceito refere-se aos casos em que a cura se apresenta inatingível, a morte iminente e os tratamentos terapêuticos adotados não apresentam benefícios à saúde do indivíduo (Oliveira \& Barbas, 2013; Silva, Souza, Silva \& Teixeira, 2014).

Destaca-se então o conceito de ortotanásia que se apresenta como uma opção intermediária entre os dilemas levantados frente aos extremos representados pela eutanásia e distanásia quando refere-se ao cuidado de pessoas em estado terminal, oferecendo a este uma morte mais equilibrada (Neves et al., 2014; Junior \& Esteves, 2019). Trata-se da morte em tempo apropriado, sem utilizar métodos terapêuticos desproporcionais e fúteis, consistindo na aceitação da morte ao permitir seu curso natural. Neste caso, o tratamento terapêutico pode ser interrompido com o intuito de evitar dores e sofrimentos, sendo respeitado o desejo do paciente ou do seu representante legal, estando associada a prestação de cuidados paliativos adequados (Mendes et al., 2020; Tavares, 2016).

Vale lembrar que os cuidados paliativos são definidos como uma abordagem multiprofissional que melhora a qualidade de vida dos pacientes e suas famílias que enfrentam problemas associados com doenças ameaçadoras de vida, através da prevenção e do alívio do sofrimento, com meios de identificação precoce, avaliação correta, tratamento da dor, e outros problemas de ordem biopsicossocial e espiritual (Alves, Cunha, Santos, \& Melo, 2019). Constitui-se em uma abordagem voltada para o ser humano em sua integralidade e necessidades, auxiliando os indivíduos na vivência e no enfrentamento da morte da melhor forma possível, sendo a abordagem que mais se aproxima do que defende a bioética no tocante ao respeito à vida humana, pois visa aliviar o sofrimento do paciente sem prolongar ou abreviar a vida, deixando que a mesma siga seu fluxo natural, promovendo conforto e qualidade de vida (Tavares, 2016; Junior \& Esteves, 2019).

Com efeito, o debate sobre os temas constituem desafios e dilemas na prática profissional em saúde, pois o Brasil apresenta aspectos limitantes relacionados à falta de legislação específica para a finitude humana, apesar de dispor de resoluções tal qual a resolução do Conselho Federal de Medicina a qual determina que:

$\mathrm{Na}$ fase terminal de enfermidades graves e incuráveis é permitido ao médico limitar ou suspender procedimentos e tratamentos que prolonguem a vida do doente, garantindo-lhe os cuidados necessários para aliviar os sintomas que levam ao sofrimento, na perspectiva de uma assistência integral, respeitada a vontade do paciente ou de seu representante legal. (Conselho Federal de Medicina no 1805, 2006, p1).

Convém salientar que as possibilidades de morte assistida que oferecem ao indivíduo alternativas no quesito são analisadas por meio de duas vertentes: uma que defende a ideia do indeclinável direito à sua vida e escolha do destino que bem entender, justificando- se mediante o princípio da dignidade da pessoa humana contido no (art. $1^{\circ}$, III da CF/88). Já a segunda corrente, aplica o direito penal, e defende a vida como o mais alto bem jurídico, como um direito inalienável (Mendes et al., 2020). Assim, alguns criticam o argumento de que a morte seria a única forma de aliviar sofrimento intolerável, pois existem sedativos e analgésicos potentes capazes de alcançar esse objetivo. Para estes, a prática da morte assistida prejudicaria o desenvolvimento dos cuidados paliativos (Kovács, 2014; F. N. Santos, 2016).

Nesse sentido, cabe analisar o artifício da morte assistida sob a luz da bioética, principalmente através do respeito à autonomia do sujeito, considerando-se que essa prática deve ter como finalidade cessar o sofrimento intenso. Dessa forma, a escolha por uma boa morte perpassa, então, pelo fim dos padecimentos causados por uma existência insuportável e penosa, que 
consegue impor ao indivíduo a uma subvida, ou seja, uma vida sem perspectiva e sem dignidade (Ugarte \& Acioly, 2014).

O processo morte e morrer com dignidade envolve o respeito às decisões do cliente, que na ocasião possa responder por si, assim como a utilização de medidas terapêuticas e farmacológicas, que aliviam a dor e o sofrimento deste. Igualmente refere-se ao bem-estar físico, emocional e espiritual, a fim de proporcionar qualidade de vida ao paciente, bem como a sua família (Junior \& Esteves, 2019).

Posto isto, é inegável o direito a uma morte digna ou à morte que segue seu curso natural. Pois este direito é congruente ao direito à vida digna, direito fundamental constitucionalmente assegurado. Diante desse retrato complexo e desafiador cabe analisar o que foi posto com base nos princípios da bioética a qual ampara as questões éticas mais discutidas e polêmicas de forma mais ponderada (Tavares, 2016).

Nesse aspecto, deve-se discutir ainda a ideia de associação da dignidade humana à preservação da vida. De fato, as possibilidades associadas ao encerramento desta carecem de cautela quanto a sua flexibilização e prática, no entanto, deve-se considerar que "a dignidade protege, também, a liberdade e a inviolabilidade do indivíduo quanto à sua desumanização e degradação". Deve-se observar que em casos de situações dolorosas, terminais ou degenerativas em que o indivíduo passa a considerar a abreviação da vida ou a recusa de intervenções que venham a prorrogá-la não qualitativamente, o prolongamento a vida distancia-se do conceito de direito, aproximando-se da concepção de dever (Barroso \& Martel, 2010).

A ideia da liberdade para morrer associa-se à morte digna relacionando-se ao conceito de autonomia. Um dos pilares da bioética, este princípio está vinculado à liberdade de escolha do paciente quanto à aceitação dos tratamentos oferecidos a sua saúde, bem como o curso a ser adotado. Destaca-se que a capacidade de decidir do sujeito infere na detenção das informações necessárias para uma escolha esclarecida (Ugarte, \& Acioly, 2014).

\section{Conclusão}

A questão da morte se tornou extremamente complexa, trazendo temas como as chamadas tecnologias da morte, do discurso transhumanista, e do tratamento e cuidado de doentes terminais. Tais questões, além de terem desdobramentos no campo da bioética, da política e do direito, levantam debates filosóficos renovados, que podem ser investigados à luz do cânone ocidental, ao qual pertencem os autores citados anteriormente. Assim, a liberdade de morrer não se trata somente de aceitar ou não um procedimento em saúde, escolher um método para acelerar a morte, tão pouco para evitá-la, mas na aceitação ou não da morte como uma etapa natural e inequívoca do ciclo da vida e o poder que o ser tem sobre si em seu próprio processo de morte.

Considerando esse poder de decidir por si em condição de total esclarecimento e em benefício próprio e de outros, a angústia que agora se apresenta tanto pode ser mais uma fonte de sofrimento (quando o próximo passo é convencer a equipe de saúde do seu desejo e fazer cumprir a sua vontade), como pode se apresentar como a angústia da etapa de convencimento da família, a qual pode ser a opositora ou a que tem o poder de decidir nas mãos.

Em qualquer situação que envolva o processo de finitude, o dilema ético estará presente e só a profunda reflexão sobre cada caso poderá indicar o melhor caminho, a qual perpassa pela pessoa, de forma que se tenha certeza de que sua decisão é permanente, havendo esgotado a análise das razões que justificariam continuar vivendo em sofrimento. Sendo uma decisão segura da pessoa, a família precisa de apoio e ajuda qualificada para ouvir, compreender, aceitar e ainda assim permanecer cuidando da pessoa. Por fim, a busca do apoio da justiça para fazer valer o direito de ter o desejo respeitado, cuja decisão envolverá a equipe de saúde, a qual também se ocupará dos trâmites e protocolos de seguimento do processo e preservação de órgãos, caso sejam doados.

Pelos argumentos apresentados neste trabalho, entende-se que o objetivo foi alcançado, na medida em que uma questão foi colocada à reflexão, apresentou-se uma visão do fenômeno morte para esclarecer qual objeto estava sendo 
discutido, os argumentos encontrados dialogam entre si, cabendo afirmar que o tema não se esgota, mas o respeito ao sofrimento, à dor e à indignidade humana torna imperioso escutar e aceitar a vontade da pessoa, acatando a liberdade que ela tem de decidir e fazer cumprir sua decisão, percebendo as circunstâncias em que as coisas acontecem.

Em torno desse dilema ainda baila a angústia de quem depende dessa decisão para salvar outras vidas pela doação de órgãos. Mas esta questão deve ser debatida em um próximo ensaio teórico.

\section{Referências}

Albuquerque, J. A. G. (1995). Michel Foucault e a teoria do poder. Tempo social, 7(1-2), pp. 05-110. https://www.scielo.br/pdf/ts/v7n1-2/0103-2070-ts-07-020105.pdf

Alves, R. S. F., Cunha, E. C. N., Santos, G. C., \& Melo, M. O. (2019). Cuidados paliativos: alternativa para o cuidado essencial no fim da vida. Psicologia: Ciência e Profissão, 39(e185734), pp.1-15. https://doi.org/10.1590/1982-3703003185734

Ariès, P. (2012). História da morte no Ocidente (Siqueira, PV, trad.): Nova Fronteira (Coleção Saraiva de Bolso).

Barroso, L. R., \& Martel, L. D. C. V. (2010). A morte como ela é: dignidade e autonomia individual no final da vida. Revista da Faculdade de Direito da Universidade Federal de Uberlândia, 38(1). http://www.seer.ufu.br/index.php/revistafadir/article/view/18530

Benedides, R. B. (2018). Eutanásia, distanásia e ortotanásia: A (im) possibilidade de (des) criminalização desses institutos. http://dspace.sti.ufcg.edu.br:8080/jspui/handle/riufcg/15435

Constituição de 1988. Constituição da República Federativa do Brasil. Diário Oficial da União. Brasília, p.1, 05 out 1988, Seção 1. http://www.planalto.gov.br/ccivil_03/Constituicao/DOUconstituicao88.pdf

Conselho Federal de Medicina. Resolução ${ }^{\circ} .1 .805$, de 28 de novembro de 2006. Estabelece que na fase terminal de enfermidades graves e incuráveis é permitido ao médico limitar ou suspender procedimentos e tratamentos que prolonguem a vida do doente, garantindo-lhe os cuidados necessários para aliviar os sintomas que levam ao sofrimento, na perspectiva de uma assistência integral, respeitada a vontade do paciente ou de seu representante legal. Diário Oficial da União. Brasília, p.169, Seção 1. https://pesquisa.in.gov.br/imprensa/jsp/visualiza/index.jsp?jornal=1\&pagina=169\&data=28/11/2006

da Maia Pawlowytsch, P. W., \& Kovalski, E. (2017). O entendimento da morte para profissionais de saúde de um hospital geral de Santa Catarina. Saúde e meio ambiente: revista interdisciplinar, 6(2), pp. 28-38. https://core.ac.uk/download/pdf/229775107.pdf

de Azeredo Orselli, H. M. Z., \& Faissel, F. X. (2020). Poder de decisão em relação ao final da vida. Revista da Faculdade de Direito da Universidade São Judas Tadeu, (8)1, 20-20. https://revistadireito.emnuvens.com.br/revistadireito/article/view/103

de Brito, M. P., \& Leal, V. E. (2015). A Autonomia da Vontade no Direito de Morrer. Pensar Direitos Humanos, p. 90. https://jus.com.br/artigos/46381/aautonomia-da-vontade-no-direito-de-morrer/2

de Jesus Barbosa, J., \& Ribeiro, C. V. (2018). O conceito de pulsão na psicanálise freudiana: considerações a partir da filosofia de martin heidegger. Revista Ideação, Edição especial, pp. 476-504. https://www.maxwell.vrac.puc-rio.br/35898/35898.PDF

de Souza Tavares, C. T. (2016). Ortotanásia e distanásia: percepções da equipe multiprofissional na unidade de terapia intensiva. Enfermagem Brasil, 15(2), pp. 68-74. https://portalatlanticaeditora.com.br/index.php/enfermagembrasil/article/view/169

dos Santos, P. R. (2016). A concepção de poder em Michel Foucault. Especiaria, 16(28), pp. 261-280. https://periodicos.uesc.br/index.php/especiaria/article/view/1504/1150

Furtado, R. N., \& Oliveira Camilo, J. A. (2016). O conceito de biopoder no pensamento de Michel Foucault. Revista Subjetividades, 16(3), 34-44. http://dx.doi.org/10.5020/23590777.16.3.34-44

Júnior, A. C. C., \& Esteves, J. C. R. (2019). Bioética e eutanásia: considerações introdutórias. InterSciencePlace, 14(4). http://www.interscienceplace.org/isp/index.php/isp/article/view/868/497

Kovács, M. J. (2015). Suicídio assistido e morte com dignidade: Conflitos éticos. Revista Brasileira de Psicologia, 2(01). https://pt.scribd.com/document/270821311/Kovacs-2015-Suicidio-Assistido-e-Morte-Com-Dignidade-Conflitos-Eticos

Kovács, M. J. (2014). A caminho da morte com dignidade no século XXI. Revista Bioética , 22 (1), 94-104. https://doi.org/10.1590/S198380422014000100011

Marreiro, C. L. (2013). Responsabilidade civil do médico na prática da distanásia. Revista Bioética, $21(2)$, 308-317. https://www.scielo.br/scielo.php?pid=S1983-80422013000200014\&script=sci_abstract\&tlng=es

Mendes, A. C., Mendes, M. J. M., Costa, G. H., Pinheiro, V. M., Pias, F. C., \& Schmitz, A. K. (2020). A polêmica da Legalização da Eutanásia no Brasil. Brazilian Journal of Development, 6(10), 79803-79814. https://www.brazilianjournals.com/index.php/BRJD/article/view/18508

Mesquita, F. J. (2019). O direito à morte: uma análise foucaultiana sobre o surgimento de Ribeirão das Neves a partir da nova capital mineira. PRACS: Revista Eletrônica de Humanidades do Curso de Ciências Sociais da UNIFAP, 12(1), pp. 93-107. http://dx.doi.org/10.18468/pracs.2019v12n1.p93-107

Oliveira, M. Z. P. B., \& Barbas, S. (2013). Autonomia do idoso e distanásia. Revista Bioética, 21(2), pp. 328-337. https://doi.org/10.1590/S198380422013000200016 
Research, Society and Development, v. 10, n. 6, e0510615435, 2021

(CC BY 4.0) | ISSN 2525-3409 | DOI: http://dx.doi.org/10.33448/rsd-v10i6.15435

Pazinatto, M. M. (2019). Direito penal médico e os hard cases: eutanásia, suicídio assistido, distanásia e ortotanásia. Direito penal e processo penal, 1(2), pp. 54-83. https://revistas.anchieta.br/index.php/direitopenalprocessopenal/article/view/1502/1381

Praxedes, A. M., Araújo, J. L. D., \& Nascimento, E. G. C. D. (2018). A morte e o morrer no processo de formação do enfermeiro. Psicologia, Saúde \& Doenças, 19(2), pp. 369-376. http://dx.doi.org/10.15309/18psd190216

Ramos, F. R., \& Franco, T. B. (2020). Potência spinoziana: resistência ao controle sobre o modo de morrer. Revista Bioética, 28(3), 455-463. http://dx.doi.org/10.1590/1983-80422020283407

Santiago, A. W. O., \& Deplagne, L. E. D. F. C. (2019). A Morte Heroica: Remanescência Mítica Grega Na Canção De Rolando. Revista Decifrar, 7(14). https://periodicos.ufam.edu.br/index.php/Decifrar/article/view/6684/5390

Santos, A. D. S. D. (2019). Ser familiar cuidador de doente com câncer em cuidados paliativos: uma análise à luz do interacionismo simbólico. http://www.bdtd.uerj.br/tde_busca/arquivo.php?codArquivo=16590

Santos, D. A., Almeida, E. R. P. D., Silva, F. F. D., Andrade, L. H. C., Azevêdo, L. A. D., \& Neves, N. M. B. C. (2014). Reflexões bioéticas sobre a eutanásia a partir de caso paradigmático. Revista bioética, 22(2), pp. 367-372. https://doi.org/10.1590/1983-80422014222018.

Santos, F. N. (2016). Bioética: Íntimo De Cada Ser Humano. Caderno de Graduação-Ciências Biológicas e da Saúde-UNIT-SERGIPE, $3(3), 27$. https://periodicos.set.edu.br/cadernobiologicas/article/view/2578

Santos, L. B. D. (2019). A perspetiva dos profissionais de saúde sobre a diretiva antecipada de vontade (Master's thesis). http://hdl.handle.net/20.500.11960/2285

Silva, J. A. C. D., Souza, L. E. A. D., Silva, L. C., \& Teixeira, R. K. C. (2014). Distanásia e ortotanásia: práticas médicas sob a visão de um hospital particular. Revista bioética, 22(2), pp. 358-366. https://doi.org/10.1590/1983-80422014222017

Tasca, M. G. (2020). A morte na antiguidade e na contemporaneidade em sêneca e ariès. Barricadas: Revista de Filosofia e Interdisciplinaridade, 1(1). http://www.periodicoseletronicos.ufma.br/index.php/barricadas/article/view/15607/8167

Ugarte, O. N., \& Acioly, M. A. (2014). O princípio da autonomia no Brasil: discutir é preciso. Revista do Colégio Brasileiro de Cirurgiões, 41(5), pp. $374-377$. https://doi.org/10.1590/0100-69912014005013. 